\title{
Exploring Adoption and Implementation of Strategic Management Tools and Techniques by Listed Companies in the Sri Lankan Context
}

\author{
Indrani, M. W. ${ }^{1}$, Naidoo, M. $^{2}$ and Wickremasinghe, G. ${ }^{2}$ \\ 1. Department of Accounting and Finance, University of Ruhuna, Sri Lanka \\ 2. Victoria University Business School, Victoria University, Australia
}

\begin{abstract}
The strategic management tools and techniques, also known as modern management accounting (MA) techniques, support managers in all stages of the strategic management process of businesses to achieve better performance. However, literature review evidenced that compared to traditional MA techniques the use of modern MA techniques is low particularly in developing countries. This study thus, explores the extent to which listed companies in Sri Lanka apply selected strategic management tools and techniques: target costing, kaizen costing, balanced scorecard and benchmarking stressing influences and variations among industry sectors with these practices. This study applies the Mixed Method Research approach with its QUAN+ qual paradigm. Using a multi-stage purposeful random sampling technique, 42 listed companies were selected demonstrating five industry sectors. Interviews and discussions were conducted preferably with Finance executives of companies to verify the responses to the survey which is the main source of data. Findings advocate that contrary to the low application of modern MA techniques shown in the literature, Sri Lankan companies demonstrate a high level of application of four techniques observed. Even if target costing is not applicable for the whole plantation sector, they demonstrate rather high application of other techniques observed as they often deal with international markets where excellent quality is very important. Findings ratify that extent of application of techniques varies among sectors, mostly induced by factors such as: the nature of products, processes, and markets; stage of the business; size of companies; and the impact of environmental changes on businesses. It concludes that overall Sri Lankan companies are in a view that these practices certainly facilitate them, in keeping aligned product prices with market prices and accompanying quality of products that are essential in surviving in such highly competitive markets while retaining a satisfactory margin securing brand reputation.
\end{abstract}

Keywords: Strategic management tools and techniques; industry sectors; listed companies; product improvement; costreduction 


\section{Introduction}

With increased global competition, improved technologies and information systems have directed businesses to use new management techniques (Baykaso_glŭ and Kaplano-glŭ 2006). Moreover, increased competition and increased costs of designing have made imperative stimulations for the organizations to search for the right products and the right methods for manufacturing the products (Sani \& Allahverdizadeh, 2012). In this process, organizations should focus on customers and identify customer demands directly to design the right products. Companies being motivating through such increased competition tend to become leaner, more responsive, and more active, with everincreasing efficiency and effectiveness to satisfy customers (Agrawal and Mehra, 1998). In the sense, through a review of literature (1990-2015), Qehaja, Kutllovci \& Pula (2017) revealed that many authors portrayed enhancing the quality and application of strategic management education as one avenue to enhance management practices.

Anna (2015) stated that managers and executives of the companies are observing appropriate tools and techniques in order to investigate the internal and external cost of the products/service, get market information, product costs, analyze customer needs and wishes, predict and assess organizational performance, so that ensuring competitive advantage. In today's fast changing economic situation, every company is trying to assess its performances regularly. For the survival, companies are considering expansions by accessing new markets; making product and price more attractive; satisfying customers; and developing new strategies. In this concern, it induced positive significant relationship between the use of management tools and technique and organizational performance (Anna, 2015).

Literature review evidenced that effective management accounting (MA) systems facilitate managers by providing useful information to make sound decisions regarding all functions of management and hence increase organizational performance (International Federation of Accountants IFAC 2005). In this concern, Cost Management is treated as an important area of accounting which involves methods of costing products and services and provides managers with information relevant to planning and control of costs in the short run and in the long run (Horngren, Dadar, \& Foster, 2003). The modern MA techniques which are also known as strategic management tools and techniques are designed and developed to support managers in all stages of the strategic management process to achieve better performance (Qehaja, Kutllovci\& Pula, 2017).

However, literature review evidenced that the use of modern MA techniques such as activity based costing (ABC), balanced scorecard (BSC), target costing (TC) is lower than that of traditional MA techniques like traditional budgeting, standard costing and variance analysis, particularly in developing countries. For 
examples, Suleiman, Ahmad, \& Alwi (2004) in a literature review of four Asian countries: Singapore, Malaysia, China and India, suggest that traditional MA techniques are seen to be less useful in the present manufacturing environment, however, the use of modern MA tools is lacking and the use of traditional MA tools remains strong in these four countries (Sulaiman et al. 2004). Also Mclellan and Moustafa (2013) found that companies in the Arab Gulf Cooperative Countries rely more on traditional MA practices than the modern MA tools such as ABC and BSC.

Moreover, through the literature review the researcher is convinced that overall MA research is insufficient particularly relating to developing countries, like Sri Lanka. Relating to modern MA techniques, as stated by Yazdifar \& Askarany (2012), a literature review of the past few decades further evidenced that almost all research has focused on studying the adoption and non-adoption of one of the modern techniques, namely $\mathrm{ABC}$, with the other techniques receiving less attention (Askarany and Yazdifar, 2007b; Askarany et al., 2010). Thus, very little empirical research appears on the application of modern MA techniques or strategic management tools and techniques by business firms particularly relating to developing countries. The above judgments have led the researcher to undertake a research project to investigate the application of modern MA techniques based on a developing country, Sri Lanka.

In this sense, Mclellan and Moustafa (2013) revealed that company characteristics play a significant role in the use of MA techniques by businesses.
Qehaja, Kutllovci \& Pula (2017) also realized that managers use strategic management tools in their workplace, but there have been differences among enterprises according to their size, sector, and country-level development. Similarly, $\mathrm{Ng}$, Harrison and Akroyd (2013) indicated that various dimensions of business size have different and somewhat opposing effects on MA practices. Yigitbasioglu (2017) also identified three factors that derive MA adaptability in organizations: the impact of top management team knowledge; team-based structures; and information system flexibility. There has been a positive association between MA adaptability and MA effectiveness (Yigitbasioglu, 2017).

Considering the above indications and settings, it is vital to investigate: the extent to which Sri Lankan listed companies apply strategic management tools and techniques namely, Target Costing, kaizen costing, Balanced Scorecards and benchmarking (BM); influences behind such practices; and whether there are significant variations with these applications among companies/ industry sectors that demonstrate different characteristics and surroundings.

\section{Literature Review}

In a literature review of four Asian countries: Singapore, Malaysia, China, and India, Sulaiman et al. (2004), revealed that the use of modern MA tools is deficient, while the use of traditional MA tools seems to be forceful in these countries. However, the authors suggests that to be successful in the present changing business world, applications of modern MA tools, such as $\mathrm{ABC}, \mathrm{BSC}$, and $\mathrm{TC}$, JIT systems are 
typically important, thereby enhancing the ability of organizations to meet global competition. Waweru, Hoque, \& Uliana (2005) presented somewhat different ideas that modern MA techniques such as $\mathrm{ABC}$ and balanced scorecard-type performance measures are used together with the traditional MA techniques, such as budgeting and standard costing in listed companies in South Africa. Through such practices, South African firms are striving to reduce waste in their production processes, and move towards the elimination of nonvalue adding activities.Waweru et al. (2005) further suggest that the crucial factor for limiting the implementation of more sophisticated MA systems is their unaffordable costs.

In these scenarios, it further deliberates on the literature focusing on four MA techniques under investigation.

\subsection{Target Costing and Kaizen Costing}

The TC was first introduced as a cost management tool in Japan in 1960s. The TC identifies as a system of profit planning and cost management that is priceled, customer-focused, designs centered, and cross-functional. It starts cost management at the initial stages of the product development and applies for the entire product life cycle by encompassing the whole value chain (Sani \& Allahverdizadeh, 2012). According to Ansari and Bell (1996), the process of TC forms a team-based proactive settings representing experts from different departments, and they work together to make decisions, so that reducing the information gap among departments and making them more responsive as they comprehend the importance of their activities (cited by Sani \& Allahverdizadeh, 2012).

Considering the importance of TC, Yazdifar \& Askarany (2012) emphasized that companies are forced by market structures of the products and services towards managing their costs in line with the competition and customer needs. The process of TC is placed on the fundamental rule; "If we cannot make the desired profit we should not launch the product". TC is a method/philosophy of considering financial, manufacturing, and customer aspects during the designing stage and supports organizations for product design decisions, thereby increasing the profit/value of the company. In achieving strategic goals, organizations use various techniques to determine customer demands and to reduce manufacturing costs. TC is an integral part of total product design/redesign process derived through strategic plans (Sani \& Allahverdizadeh, 2012). Moreover, Zengin \& Ada (2010) emphasized that TC is not just a cost management technique, but a strategic management tool involving in other valuable managerial tools and techniques such as quality function deployment and value chain.

Relating to the application of TC, Yazdifar \& Askarany (2012), through a survey in the UK, Australia (AU) and New Zealand (NZ) found that the extent of adoption of TC is relatively low depicting only $17.9 \%$ in Australia, $18.3 \%$ in New Zealand and $16.7 \%$ in the UK. Besides, some firms have introduced TC on a trial basis: $5.5 \%$ in AU, $2.8 \%$ in NZ, and $9.1 \%$ in the UK. Contrary to the literature, Yazdifar \& Askarany (2012) specified that TC is equally important for both manufacturing 
and service firms, however, the significant variations seemed between industries with more tendency for manufacturing firms proceed with the higher level of implementation of TC than service firms.

According to Joshi (2001), despite the advantages of TC, even many years after its introduction, its adoption seemed at low. Strangely, the adoption rates of TC in Western and Asian countries reported in the literature are much lower than those of Japanese firms probably due to several factors, including cultural differences, and therefore suggesting further studies (Yazdifar \& Askarany, 2012). Similarly, Sani \& Allahverdizadeh (2012) expressed that TC has been given much more attention in Japan, but is increasingly being taken up in the West. For example, Lorino (1995) stated that over $80 \%$ of large companies in the assembly industries applied TC in Japan while Ernst \& Young and The Institute of Management Accountants- IMA (2003) found that $26 \%$ of IMA member firms had adopted TC in the US.

Similarly, as depicted by Chantal and Langfield-Smith (1998), of 78 large Australian manufacturing firms 38\% had employed TC, whereas Dekker and Smidt (2003a, 2003b) reported that $59.4 \%$ of Dutch firms listed in the Amsterdam Stock Exchange use TC (cited by Sani \& Allahverdizadeh, 2012). Wijewardena and De Zoysa (1999) also found that of the 11 MA practices investigated across a sample of 209 Japanese manufacturing firms, TC was observed as the most significant practice, whereas of the sample of 225 Australian manufacturing firms, TC ranked only tenth in importance among the $11 \mathrm{MA}$ practices.
In a review of literature, Ansari, Bell, \& Okano (2007) reported that TC is being progressively adopted by many leading firms worldwide, demonstrating certain dispersion in East Asia (India and Malaysia). Also, several companies in the USA, like Chrysler and Caterpillar, attribute their financial success in the mid-1990s to the adoption of TC; exemplifying that TC is fairly mature in Japanese assembly industries and fairly young in the USA and Europe. Ansari et al., (2007) suggest that underestimation of the potential of TC by many managers may influence the low adoption.

Sulaiman et al. (2004), through a literature review, stated that TC provides continuous improvement both at the design and production stage, enabling companies to create competitive advantage. Similarly, Sakurai (1989) detected that TC helps Japanese companies to maintain their competitiveness. In India, TC has shown potential, but in terms of its benefits, the survey ranked it fourth; however, in terms of its future emphasis, it was ranked first, indicating a possible increase in its use in the future. According to Tho, Md. Isa \& Ng (1998), 41\% of respondents have implemented TC in Malaysia and 4\% would implement it in the next five years (Sulaiman et al., 2004).

As of TC, kaizen has a Japanese philosophy and refers to the process of seeking continuous improvement. Some Japanese companies link a TC planning process with a kaizen process when the products are in the process. Companies practicing in more developed markets with longer product life cycles, give more emphasis on kaizen during operations. Kaizen essentially tries to ensure that everyone in the company continually re- 
considers how the task is undertaken and whether there is a better way of doing it. Other companies with short to medium product life cycles, pay more attention to TC. It seems that their approach to continuous improvement extent through several generations of products at different stages of design and development (i.e. different stages of target costing). (Sani \& Allahverdizadeh, 2012).

\subsection{Balanced Scorecards}

Kaplan and Norton (1992) initially proposed 'balanced scorecards' as a tool for measuring business performance integrating financial and non-financial measures of performance which reported across four different dimensions: a financial perspective, a customer perspective, an internal business perspective, and learning and growth perspective. Kopecka (2015) revealed that many researchers widely investigated BSC from its inception and found advantages and disadvantages of the approach relating to communication, integration and indicators of measurement. It further depicted that BSC has been developed far from the basic concepts, but the framework is diverse and unclear on implementation that may mislead firms in implementing their processes and taking decisions (Kopecka, 2015).

Abdel-Kader\& Luther (2006) stated that over $75 \%$ of companies consider financial measures of performance to be fully important and non-financial measures of performance to be highly important, particularly regarding customer satisfaction. Also, they identified an impression that is more talked about BSC than its application and concluded that performance measurement (PE)is still desperately

International Journal of Accounting \& Business Finance dominated by financial figures. Sulaiman et al. () also emphasized that PE is an important function of MA, mostly in companies with a divisional sized organizational structure. They suggest that it is not enough to relying on accounting-related measures, i.e., ROI, economic value added (EVA) in measuring divisional performance, and thus proponents of the BSC argued that nonfinancial measures should also be used.

Consequently, many companies are currently focusing on both accounting and non-financial related measures. For example, according to '. study in India, all respondents used ROI, variance analysis, and divisional profit to measure performance, and a considerable proportion $(53 \%)$ of respondents also focused on nonfinancial measures, i.e., customer satisfaction, product quality. In addition, a high proportion $(80 \%)$ of companies reported that they evaluate performance based on customer satisfaction. However, reveal that financial-based performance measures remain the preferred techniques as far as Indian companies are concerned.

Concentrating on views and practice of BSC in the four countries considered, Sulaiman et al. () stated that the BSC has gained increasing popularity since its introduction. Similarly, scholars and practitioners have argued that relying solely on accounting metrics may not be sufficient to evaluate performance. Thus they assume that, firms need to focus on all perspectives of BSC to achieve a balance.

Moreover, Atkinson, Waterhouse, $\&$ Wells recognized the BSC as one of the most significant developments in MA, and found a positive relationship between size and BSC usage: the bigger the company, the more practical it is to use BSC to support 
strategic decision making. Sulaiman et al. () also noticed that ' study somewhat supports this contention: large companies tend to use newly developed MA techniques to a greater extent than medium-sized enterprises. Sulaiman et al. () found that the use BSC in Indian companies is higher (40\%) than that of Malaysian companies (13\%), but surveys in Singapore and China did not test the BSC. Sani \& Allahverdizadeh (2012) emphasized that the thrust behind the development of BSC came from dissatisfaction with reliance on just financial statements, especially the Income Statement and Balance Sheet, as the main source of determining a corporate group or division's position.

\subsection{Benchmarking}

According to Hurreeram (2007), benchmarking is a systematic and continuous process of searching, learning, adapting, and implementing the best practices from within own organization (internal BM) or from other organizations (external BM) towards attaining superior performance. On the other hand, Benchmarking encourages a company to adopt new methods, ideas, processes, and practices to improve effectiveness, efficiency, and performance (Deros, yusof \& Salleh, 2006). Accordingly, the objective of benchmarking is to understand and evaluate the current position of a business or organization concerning the "best practice" and to identify areas and sources of performance improvement.

Asrofah, Zailani \& Fernando (2010) revealed that the popularity of benchmarking has grown during the last five years. Based on the case studies and reports in the USA in the late 1990s, all Fortune 500 companies were using benchmarking on a regular time basis (Kumar and Chandra, 2001). However, due to the lack of a complete understanding of benchmarking, not all organizations find it easy to employ the tools effectively. Benchmarking is emerging in leading-edge companies as an information tool to support continuous improvement and to gain competitive advantage. To benchmark effectively, a company needs a strong strategic focus and some flexibility in achieving management's goals. To implement benchmarking effectively, adequate planning, training, and open inter-departmental communication are needed (Asrofah et al., 2010).

B a s e d on Indonesian manufacturing industries, Asrofah et al., (2010) suggest general requirements that an organization needs to have a successful benchmarking process: top management commitment and support, a good understanding of the manufacturing operations and requirements for improvement, willingness to share information with benchmarking partners, and dedication to ongoing benchmarking efforts. Authors also emphasized that from an organizational point of view, attention should be given to improving compatibility, employee innovativeness, and government intervention so that the best practices of benchmarking can be used proactively as a strategic tool. Meanwhile, Meybodi (2009) advocated that along with the increased use of benchmarking, many researchers focused more on performance measures and setting targets and they found that many companies are more consistent in choosing benchmarking performance measures that are aligned with organizational strategy.

Asrofah et al. (2010) also found that the age of the company has a positive relationship with benchmarking effectiveness. For 
instance, the longer the company has been established means that it may have longer strategic plans, and a more established complexity of the product and innovative employees. The findings of this study have shown that there is a significant relationship between the manufacturing process, organizational and environmental factors, and benchmarking effectiveness.

This study is an attempt to contributing to these gaps in the literature.

\section{Research Objectives and Methodology}

\subsection{Research Objectives}

The main objective of this study is to explore the extent to which listed companies in the Sri Lankan context apply strategic management tools and techniques; explicitly target costing, kaizen costing, balanced scorecard and benchmarking stressing accompanying influences and variations among industry sectors with these practices.

\subsection{Methodology}

\subsubsection{Research approach}

This study applies a MixedMethod Research (MMR) approach and comprises one paradigm out of eight paradigms of MMR designs: QUAN + qual (Morse, 2010, p.341). MMR takes place

when the researcher cannot depend on either a quantitative or a qualitative method alone and must buttress his or her findings with a method drawn from the other research strategy (). The researcher was motivated to use the MMR approach in this study as it seemed more appropriate in producing complete and expressive analysis and a thorough interpretation of findings.

\subsubsection{Theoretical drive, core component and supplemental component}

The study primarily employed a face-to- face questionnaire survey. To corroborate the responses to the survey, interviews, and discussions were conducted with company finance executives concurrently to the survey. Accordingly, as described by Morse (2010) in MMR designs, the theoretical drive for this study is identified as quantitative (indicated as QUAN) as it would be the complete method and thus indicates as the 'core component'. Then, the part of the question that cannot be answered by the selected quantitative method is addressed by either a qualitative or quantitative strategy, conducted at the same time (called simultaneous, shown with $\mathrm{a}+$ sign) or else immediately following the core component (called sequential, indicated with an arrow $\rightarrow$ ). Thus, the supplemental component of this study is identified as 'qual'. Accordingly, it identifies 'QUAN + qual' as the research approach for this study.

\subsubsection{Population, sample and sampling}

This study is based on 42 listed companies demonstrating five industry sectors: food, beverages and tobacco- F \& B $(8 / 22)$, chemicals \& pharmaceuticalsCHEM (3/12), diversified holdings- DVS (5/16), manufacturing -MNF (18/39), and plantation- PLT $(8 / 20)$ out of 20 sectors according to the Colombo Stock Exchange (CSE) in Sri Lanka. Accordingly, the population of this study comprises of 109 companies. Here, it applied mainly the multi-stage purposeful random sampling technique and thus, the sample decisively 
consists only of manufacturing and manufacturing-related industries. Because these five sectors are more relevant for this study than other sectors that primarily engage in services. The researcher first, purposefully selected five industry sectors from 20, and then individual companies were selected by applying non-random sampling techniques, such as snowball sampling, convenience sampling, and purposeful sampling. Sampling was made considering factors such as the accessibility to companies, the applicability of businesses to the research area and types of data and information required, and thus the researcher was able to select the most apposite sample for the study.

\subsubsection{Data collection and analysis}

The study applied a 'personal visit approach' to each company to collect data, securing an acceptable response rate and quality of data. Data were collected mainly through a face-to-face questionnaire survey, and further interviews and discussions were conducted simultaneously with the same respondents (mostly the finance executives i.e. finance director, finance manager, finance controller, DGM finance) of sampled companies. The researcher intentionally contacted senior management as maximum as possible, (approximately $80 \%$ ), and the rest denote the middle level i.e. management accountants and/or financial accountants. Because the researcher assumed that with massive knowledge, competencies and experience that the senior management possesses, it is easy to obtain ample interpretations for the responses to the survey further to descriptive-analytical answers to queries made on the phenomena under investigation. To make this data collection process more efficient and convenient, the researcher used a voice recorder with the permission of respondents.

According to Morse (2010), there are two points of interface available in $\mathrm{MM}$ design for integrating core and supplemental components to form an expressive broad analysis and interpretations: (i) Analytical point of interface that involves in transforming qual data into numerical form; (ii) Results point of interface that adding qual data to QUAN results. In this analysis, Results point of interface was identified as the suitable position for integrating core component 'QUAN' into supplemental component 'qual'. Because it realizes the hardness of transforming the qualitative data and information into numerical form, but it has a possibility adding qualitative data to QUAN results to obtain meaningful comprehensive analysis and interpretations for the study. In such scenario, the survey data were tabulated and analyzed using SPSS software, frequency tables, and Fisher's exact test and, 'thematic analysis' and 'content analysis' were employed in the analysis of descriptive data.

\section{Data Analysis and Findings}

This section elaborates on the level of adoption of strategic management tools and techniques by listed companies by comparing and contrasting them with the pervious findings. It also pinpoints influences and variations between companies/ industry sectors with such practices.

\subsection{Target Costing}

The survey evidenced that the application of TC in Sri Lankan listed companies is above average (62\%) signifying all sectors considered except the 
PLT sector. Contrary to the low application found in the literature in the case of developing countries, and sometimes developed countries, the findings show a rather high application of TC rating 'often/always' by $45 \%$ (19 companies)and 'sometimes' by $17 \%$ (7 companies), whereas $38 \%$ (16 companies) never/rarely apply it. Relating to the adoption of TC, for example, Waweru et al. (2005) reported 6.4\% in South Africa, Drury et al. (1993) 26\% in the UK, and Chenhall and Smith (1998) 38\% in Australia, and Yazdifar \&Askarany (2012) reported $17.7 \%$ on average in three countries: the UK, Australia, and New Zealand. In contrast, Sakurai (1989) and Larino (1995) reported 79\% in Japan.

In applying $\mathrm{TC}$, the CHEM sector reports $100 \%$ always/often; DVS sector $80 \%$ always/often and $20 \%$ sometimes; the F\&B sector $-62.5 \%$ often/always and $12.5 \%$ sometimes. Apart from the PLT sector ( $0 \%)$, the lowest application appears in the MNF sector - 39\% always/often and 28\% sometimes. Some respondents state that they occasionally adopt TC for certain products depending on its practicability for their diversified product lines in operation, suggesting that it is not practical to apply TC for all product lines in a similar manner; instead, the applicability of TC typically depends on the nature of products and their market positions.

In this study, Fisher's exact test illustrates that there is a significant relationship between responding companies who applied TC and their industry sector, showing a $100 \%$ confidence level $(P=0.00)$. Because, unlike other sectors, the whole PLT sector does not apply TC mainly due to the specific nature of price determination and regular fluctuations of those prices (i.e., weekly, fortnightly), and markets that they mostly deal with (export markets) all of which are subject to no control by individual companies. The PLT sector has to adopt prices for its products from respective auctions (i.e. Tea auction, Rubber auction) which are determined weekly or fortnightly based on demand and supply, and the quality and brands. Thus, price determinations are probably made outside the control of individual companies so that typically not allied with associated costs at all, but conforming to demand and supply and quality and brands. Zero application of TC in the PLT sector might also be due to its inability to make adjustments to the cost of production because of agricultural products such as tea and rubber, on which weather changes may have a significant impact on product costs. All these appear uncontrollable, but are the most persuasive factors in TC.

Finance manager of a leading beverage company in the F\&B sector indicated their practice:

We apply TC in designing product costs and prices and determining margins accordingly. As a result, sometimes we can keep higher margin and other times lower margin; however, we do not produce any product for markets with no margin in any circumstance.

Consistent with the findings of on MA practices of large manufacturing companies in Japan, these findings identify that, as for the manufacturing stage, Sri Lankan companies devote considerable attention to cost planning and cost reduction tools through the application of TC.

Finance manager of one company dealing with durable products in the MNF sector stated:

We apply TC based on imported market prices, as we have to sell our 
products to the head office of the group who import the same products with imported brands and sell them together with our brands in the same markets. So, we are operating in a highly competitive market with other local and imported brands, but we are still in the market successfully competing with such imported brands.

Thus, the findings suggest that TC is more appropriate for products with competitive markets, as it seems to be very important in keeping aligned product prices with market prices and accompanying quality of products to survive in the market. Supporting this view, Sulaiman et al. (2004), in a literature review, reported that TC is supposed to provide companies with a competitive advantage because TC enables them to make continuous improvement both at the design and production stages. Moreover, this suggests that, as far as the nature of products and cost/benefit criterion are concerned, TC is more appropriate to apply for durable products with competitive markets and for particular product categories, such as certain brands of beverages aimed at a specific target group of customers, than would be the case for consumer products such as food products.

\subsection{Kaizen Costing}

The findings show that $62 \%$ (36\%often/always and $26 \%$ sometimes) of companies adopt Kaizen costing. However, there is greater interest in the MNF sector in adopting the technique by $78 \%$ of companies, as most are involved in durable products like refrigerators, washing machines, building materials and cabals which require thorough inspections and modifications throughout the process, demanding application of Kaizen costing, in order to maintain the quality of output, enabling firms to compete in the markets. The costs associated with those durable products are higher than those of consumer products and thus the necessity and relevance of this technique is higher for durable products than for consumer products like foods. Therefore, those companies in the MNF sector are undoubtedly compelled to apply Kaizen costing, to retain a satisfactory margin through minimizing waste that has occurred due to quality defects, and thereby it remains in competitive markets, securing brand reputation.

The high application in the PLT sector $(63 \%)$ is probably because firms often deal with international markets where excellent quality is very important. In contrast, the lowest application (33\%) is in the CHEM sector, while moderate application appears in both the F\&B and DVS sectors demonstrating $50 \%$ and $40 \%$ respectively. Fisher's exact test reveals no significant relationship between industry sector and adoption of Kaizen costing, but the relationship is significant at a $91.4 \%$ confidence level $(P=0.086)$.

Therefore, the findings suggest that, as for target costing, the application of Kaizen costing mostly depends on the nature of products and their market position, and more on durable products rather than consumer products, and products dealt with in foreign markets rather than local markets. However, this does not mean that other companies competing in local markets and manufacturing consumer products have no need to apply Kaizen costing; such companies may also require Kaizen costing to get a better quality outcome and hence 
high customer satisfaction whilst minimizing resources consumed in the process (as in the case of beverages). One large leading company in manufacturing beverages of high quality with a worldwide brand reputation stated that it essentially follows concepts of Kaizen costing at each stage of the production process because of deep concern about the premier quality of output.

\subsection{Balanced Scorecards (BSC)}

Despite the low level of application of BSC found in some of the literature relating to developing countries, for examples; $21.2 \%$ in South Africa (Waweru et al., 2005); 13\% in Malaysia; and $40 \%$ in India (Sulaiman et al., 2002), this study finds a high level of application of BSC $(64.3 \%$ or 27 companies) for performance evaluation (PE). Supporting these findings, Burns et al. (1999) indicated that $60 \%$ of companies in the UK used non-financial measures. Further, Hoque and James (2000) revealed a significant level of practice of BSC approaches (perspectives) in Australian manufacturing firms. Also, Horngren, Foster, Datar \& Uliana (1999) found extensive use of non-financial measures of performance in South African firms.

The findings show that of 27 companies that apply BSC, 16 companies practice it 'as a model' and the rest 'not as a model'; there is a greater tendency towards adopting BSC in large companies (71\%) than medium-size companies $(45.5 \%)$, as illustrated in Table 1. Supporting these findings, Hoque and James (2000) found a positive relationship between the size of companies and BSC usage: the bigger the company, the more practical it is to use BSC to support its strategic decision making. In the present study, one large beverage company stated that it applies BSC as a different model specific to its businesses. Also, a large diversified company in the DVS sector stated that as a multi-national company it applies BSC with greater attention for all perspectives.

Table 1 Comparison of practices of BSC in large and medium-size companies

\begin{tabular}{lccccc}
\hline Size & $\begin{array}{c}\text { Practiced (Number of Companies) } \\
\text { As a model }\end{array}$ & $\begin{array}{c}\text { Not practiced } \\
\text { (No. of } \\
\text { Companies) }\end{array}$ & Total & $\begin{array}{c}\text { Percentage } \\
\text { of application }\end{array}$ \\
\hline Large & 12 & 10 & 9 & 31 & $71.0 \%(22 / 31)$ \\
Medium & 4 & 1 & 6 & 11 & $45.5 \%(5 / 11)$ \\
Total & 16 & 11 & 15 & 42 & $\begin{array}{c}64.3 \%(27 / 42) \\
(\text { On average })\end{array}$ \\
\hline
\end{tabular}

Fisher's exact test shows that there is no significant relationship between adoption of BSC and industry sectors $(P$ value $=0.751)$, as there seem to be slight differences across industry sectors in adopting BSC: in DVS $80 \%$, in F\&B $75 \%$, in PLT $62.5 \%$, in MNF 61\%, and CHEM $33 \%$.

Considering four perspectives of the BSC, these findings show the highest interest in financial perspectives and slightly 
lower in customer perspectives and business process perspectives, while the lowest attention is in the learning and growth perspective. Waweru et al. (2005) indicate exactly the similar ranking for the importance of these four perspectives, suggesting that, as empirical evidence reveals (Ittner, Larcker \& Rajan, 1997; Hoque and James 2000; Hoque et al.2001), the financial perspective remains the dominant measure of performance in companies worldwide.

The findings further show that overall Sri Lankan companies still pay lower attention to modifying the BSC (33\%, 9 companies out of 27), however, the PLT sector has already paid great attention to this aspect (80\%), as shown in Table 2 .

Table 2 The adoption of the BSC and its modifications

\begin{tabular}{lccccccc}
\hline $\begin{array}{l}\text { Industry } \\
\text { Sector }\end{array}$ & \multicolumn{3}{c}{$\begin{array}{c}\text { Adoption of BSC } \\
\text { (No. of Companies) }\end{array}$} & \multicolumn{3}{c}{$\begin{array}{c}\text { If Yes, modifications to the } \\
\text { BSC }\end{array}$} & $\begin{array}{c}\text { Percentage of } \\
\text { modifications( } 1: 2)\end{array}$ \\
& Yes $^{\mathbf{1}}$ & No & Total & Yes $^{2}$ & No & Total & $\%$ \\
\hline F\&B & $\mathbf{6}$ & 2 & 8 & $\mathbf{2}$ & 4 & 6 & $331 / 3$ \\
CHEM & $\mathbf{1}$ & 2 & 3 & $\mathbf{1}$ & 0 & 1 & 100 \\
DVS & $\mathbf{4}$ & 1 & 5 & $\mathbf{1}$ & 3 & 4 & 25 \\
MNF & $\mathbf{1 1}$ & 7 & 18 & $\mathbf{1}$ & 10 & 11 & 9 \\
PLT & $\mathbf{5}$ & 3 & 8 & $\mathbf{4}$ & 1 & 5 & 80 \\
Total & & & & & & & $\mathbf{3 3} \mathbf{1 / 3}$ \\
/Average & $\mathbf{2 7}$ & $\mathbf{1 5}$ & $\mathbf{4 2}$ & $\mathbf{9}$ & $\mathbf{1 8}$ & $\mathbf{2 7}$ & $\mathbf{3}$ \\
\hline
\end{tabular}

Moreover, four companies in the MNF sector are planning to attend to this modification of the BSC shortly, as they have realized the importance of this aspect too.

Accordingly, these findings suggest that the tendency of Sri Lankan companies to adopt their own KPIs that are mostly applicable for $P E$ purposes, because they precisely match with specific characteristics of individual companies, which encourages the high application of the BSC for PE. It further suggests that Sri Lankan listed companies tend to focus more on the financial consequences of operations whilst satisfying customer needs through the process of PE rather than on future growth through leaning. Yet the findings demonstrate the least importance accorded training and learning purposes of PE (20\%).

\subsection{Benchmarking}

The findings reveal that Sri Lankan companies practice $\mathrm{BM}$ at an above-average level, with a slightly higher adoption for internal $\mathrm{BM}$ rating 'often/always use' by $66.7 \%$ (28 companies) than for external BM rating 'often/always use' by $52.4 \%$ (22 companies). Concerning internal BM, the findings suggest that companies tend to demonstrate best practices by certain division/s or by individuals/groups of persons in both manufacturing and nonmanufacturing activities to all others in the company and motivate them to adopt those best practices for their processes for higher performance. The findings further confirm that companies can typically recognize such 
best practices at monthly meetings through discussions on the progress of each division and influential factors.

This also suggests that companies who deal with export markets tend to adopt external $\mathrm{BM}$ by reviewing best practices that can be found among competitors in local and foreign markets, as they realized that otherwise, they cannot survive in such highly competitive international markets. For example, companies in the PLT sector (50\% 'often/always' and another 50\% 'sometimes' use external BM) continuously address best practices of competitors in local and foreign markets and they all (100\%) 'often/ always' concentrate on internal BM, too, to compete in foreign markets. Also, companies, particularly in the growing stage or newly established companies are stimulated by their competitive markets to find the best practices followed by leading companies towards improving the quality of products and processes while maintaining satisfactory margins. In this concern, Asrofah et al. (2010) emphasized another aspect that the age of the company has a positive relationship with benchmarking effectiveness.

\section{Discussions and Conclusions}

With increased global competition, manufacturers are forced to use creative operational strategies to keep desired profitability. Cost management strategies are the most important managerial tools and techniques applied by companies to survive in the competitive markets while keeping satisfactory profit margin in their businesses (Zengin \& Ada, 2010). In this setting, this study explores the level of application of selected strategic management tools and techniques: target costing, kaizen costing, balanced scorecard, and benchmarking, by listed companies in Sri Lanka stressing associated influences and variations among industry sectors with these practices. MMR approach was followed in the study as it seemed more appropriate in producing complete and expressive analysis and a thorough interpretation of findings.

This study concludes that contrary to the low application found in the literature in the case of developing countries, and sometimes developed countries, Sri Lankan listed companies show a rather high application of TC (62\%) signifying all sectors considered except PLT sector. It suggests that it is not practical to apply TC for all product lines in a similar manner; instead, the applicability of TC typically depends on the nature of products and markets. For example, whole PLT sector does not apply TC mainly due to its inability to adjust to cost of production because of agricultural products such as tea and rubber, on which weather changes may have a significant impact on product costs. This inability of PLT sector is further due to the specific nature of price determination and regular fluctuations of those prices. Consistent with findings of, it concludes that Sri Lankan companies devote considerable attention to cost planning and cost reduction tools through the application of TC. Supporting views of Sulaiman et al. (2004), this suggests that TC is more appropriate to apply for durable products with competitive markets than consumer products.

The findings suggest that Sri Lankan companies adopt Kaizen costing at above- 
average level(62\%) showing a greater interest in the MNF sector (78\%) than others, as most in MNF sector are involved in durable products which require thorough inspection and modification throughout the process so that enabling firms to compete in the markets with high-quality products. In the sense, the PLT sector (63\%) also demonstrates a high application of kaizen costing as they often deal with international markets where excellent quality is very important.

Despite the low level of application of BSC found in some of the literature relating to developing countries, findings show a high level of application of BSC with respect to PE (64.3\%) in Sri Lankan companies with a greater tendency towards adopting BSC in large companies than medium-sized companies (see Table 2). Supporting these findings, Hoque and James (2000) found a positive relationship between the size of companies and BSC usage. Even though overall Sri Lankan companies still pay lower attention to modifying the BSC, (but PLT sector has paid more attention to this $-80 \%$ ), it concludes that there is a tendency of Sri Lankan companies to adopt their own KPIs that are mostly applicable for PE purposes, because they precisely match with specific characteristics of individual companies. It further suggests that Sri Lankan listed companies tend to focus more on financial consequences of operations whilst satisfying customer needs through the process of PE rather than other perspectives. Waweru et al. (2005) indicated exactly the similar ranking for the importance of these four perspectives.

The findings suggest that Sri Lankan companies practice BM at an above- average level, with a slightly higher adoption for internal BM than for external BM. They typically discuss and recognize such best practices and influential factors at monthly progress meetings. Companies dealing with export markets and companies particularly in the growing stage or newly established companies tend to adopt external $\mathrm{BM}$ by reviewing best practices.

In conclusion, it emphasizes that contrary to the low application of modern MA techniques (strategic management tools and techniques) shown in the literature particularly relating to developing countries, Sri Lankan companies demonstrate a high level of application of four techniques observed. This tendency is probably due to the necessity and relevancy of those techniques to their products and markets they are dealing with in local and foreign markets.

The findings confirm that Sri Lankan listed companies inevitably compelled to apply those techniques like TC, kaizen costing, as they have realized that these techniques are more appropriate and important for their products particularly durable products with high costs and long processes, and with competitive markets. Even if the whole PLT sector does not apply TC due their inapplicability as describe above, they demonstrate a high application of other techniques as they often deal with international markets where excellent quality is very important. Also, it shows a greater tendency to adopt BSC in large companies probably due to their high capacity, strength and need, compared to medium-sized companies. And, tendency of Sri Lankan companies to adopt their own KPIs suggests that they always try to 
precisely match their performance with specific characteristics of individual companies. Also, considerable attention given by listed companies to adopt $\mathrm{BM}$ induces the importance and relevancy of such practices for businesses dealing with highly competitive local and foreign markets, and as well as for newly established companies and businesses in growing stage.

Accordingly, it evidences that the extent of application of techniques varies among sectors, mostly induced by factors such as the nature of products, processes, and markets, stage of the business, size of companies, and impact of environmental changes. It concludes that overall Sri Lankan companies are in a view that these practices certainly facilitate them, in keeping aligned product prices with market prices and accompanying the quality of products that are essential in surviving in such highly competitive markets while retaining a satisfactory margin and securing brand reputation.

\section{References}

Abdel-Kader, M., \& Luther, R. (2006). Management accounting practices in the British food and drink Industry, British Food Journal, 108 (5), 336357.

Agrawal, S.P., \& Mehra, S. (1998). Cost management system: an operational overview. Managerial Finance 24 (1), 60-78.

Anna, A. (2015). Strategic management tools and techniques and organizational performance: Findings from the Czech Republic, Journal of Competitiveness, 7(3), 19-36.

Ansari, S.L., Bell, J.F., Okano, H. (2007). A review of literature of target costing and cost management. In: Chapman, C.S., Hopwood, A.G., Shields, M.D. (Eds.), Handbook of MA Research, 2, Elsevier, Oxford, 507-530.

Asrofah, T., Zailani, S., \& Fernando, Y. (2010). Best practices for the effectiveness of benchmarking in the Indonesian manufacturing companies. Benchmarking: An International Journal, 17(1), 115-143.

Atkinson, A.A., Waterhouse, J.H. \& Wells, R.B. (1997). A stakeholder approach to strategic performance measurement, Sloan Management Review, 38(3), 25 37.

Baykaso_glŭ, A., \& Kaplano_glŭ, V. (2007). A service-costing framework for logistics companies and a case study. Management Research News, 30 (9), 621-633.

Bryman, A. \& Bell, E. (2007). Business Research Methods, Second edn, Oxford University Press, NewYork.

Burns, J.M., Baghurst, P.A.,Sawyer, M.G., McMichael, A.J., Tong, S. 1. (1999). Lifetime low-level exposure to environmental lead and children's emotional and behavioral development at Ages11-13 Years: The Port Pirie Cohort Study. American Journal of Epidemiology, 149 (8), 740-749.

Chenhall, R. H., \& Langfield-Smith, K. (1998). Adoption and benefits of management accounting practices: an Australian study, Management Accounting Research, 9(1), 1-19.

Deros, B.M., Yusof, S.M., \& Salleh, A.M. $\left(\begin{array}{llll}2 & 0 & 0 & 6\end{array}\right)$. B e n c h marking 
implementation framework for automotive manufacturing SMEs, Benchmarking: An International Journal, 13(4), 396-430.

Drury, C., Braund, S., Osbourne, P., \& Tayles, M. (1993). A survey of management accounting practices in the UK manufacturing companies, The Chartered Association of Certified Accountants, London, Chapter 6, 4148.

Hoque, Z., \& James, W. (2000). Linking

balanced scorecard measures to size and market factors: Impact on organizational performance, Journal of Management Accounting Research, 12, $1-17$.

Hoque, Z., Mia, L., \& and Alam, M. (2001). Market competition, computer-aided manufacturing and use of multiple preformance measures:an empirical study, The British Accounting Review, 33 (1), 23-45.

Horngren, C. T., Datar, S. M., \& Foster, G. (2003). Cost accounting: A managerial emphasis. Upper Saddle River, NJ: Prentice Hall.

Horngren, C.T., Foster, G., Datar, S.M., \&

Uliana, E.(1999). Cost Accounting in South

Africa, A managerial emphasis, PritiseHall, South Africa.

Hurreeram, D.H. (2007). Manufacturing strategy auditing for garment making companies, Benchmarking: An International Journal, 14 (3), 272-88.

International Federation of Accountants IFAC (2005). Environmental Management Accounting: International Guidance Document, International Federation of
Accountants, New York, USA.

Ittner, C. D., Larcker, D. F., \& Rajan, M. V. (1997). The choice of performance measures in annual bonus contracts, The Accounting Review, 72 (2), 231255.

Joshi, P.L. (2001). The international diffusion of new management accounting practices: the case of India, Journal of International Accounting, Auditing and Taxation, 10 (1), 85-109.

Kaplan, R., \& Norton, D. (1992). The Balanced scorecard: Measures that derive Performance, Harvard Business Reviews (January- February), 21-79.

Kopecka, N. (2015). The Balanced Scorecard Implementation, Integrated Approach and the Quality of its Measurement, Procedia Economics and Finance , 25, 59-69.

Kumar, S., and Chandra, C. (2001). Enhancing the effectiveness of benchmarking in manufacturing organizations, Industrial Management \& Data Systems, 101(2), 80-89.

Langfield-Smith, K. (2007). A review of quantitative research in management control systems and strategy, In Chapman, C.S., Hopwood, A.G. and Shields, M.D. (Eds), Handbook of Management Accounting, 2, Elsevier, Oxford, 753-84.

Lorino, P. (1995). Target costing practices and implementation, International Federation of Accountants: Articles of Merit. /www.ifac.org/Standards And G $\mathrm{u} \quad \mathrm{i}$ dance/FMC/ArticlesOfMerit95/AOM 
95 09.html. Managerial Emphasis, Printise-Hall, South Africa.

Mclellan, J. D.,\& Moustafa, E. (2013). An exploratory analysis of management accounting practices in the Arab Gulf Cooperative countries, Journal of Islamic Accounting and Business Research, 4(1), 51-63.

Meybodi, M.Z. (2009). Benchmarking performance measures in traditional and just-in-time companies, Benchmarking: an International Journal, 16(1), 88-102.

Morse, J. (2010). Procedures and practice of mixed method design: Maintaining control, rigor, and complexity, Sage Handbook of Mixed Methods in Social \& Behavioural Research, 2nd ed. Thousand Oaks: Sage, 339-53.

Ng, F. A., Harrison, J. \& Akroyd, C. (2013). A revenue management perspective of management accounting practice in small businesses, Meditari Accountancy Research, 21(2), 92-116.

Qehaja, A.B., Kutllovci, E. \& Pula, J. S. (2017). Strategic Management Tools and Techniques Usage: a Qualitative Review, Acta Universitatis Agriculturae et Silviculturae Mendelianae Brunensis, 65(2), 585600 .

Sakurai, M. (1989). Target costing and how to

use it. Journal of Cost Management (summer): 39-50.

Sani, A. A., \& Allahverdizadeh, M. (2012). Target and Kaizen costing, International Journal of Mechanical and Industrial Engineering, 6(2), 171-
177

Sulaiman, M.B., Ahmad, N.N.N., \& Alwi, N. (2004). Management accounting practices in selected Asian countries: A review of the literature, Managerial Auditing Journal, 19 (4), 493-508.

Tho, L. M., Md. Isa, C. R., \& Ng, K. T. (1998). Manufacturing environment, cost structures and management accounting practices: some Malaysian evidence. Akauntan Nasional Journal, 3-12.

Waweru, N.M., Hoque, Z. \& Uliana, E. (2005). A survey of management accounting practices in South Africa, International Journal of Accounting, Auditing and Performance Evaluation, 2(3), 226-263.

Wijewardena, Hema \& De Zoysa, Anura, (1999). A comparative analysis of management accounting practices in Australia and Japan: An empirical investigation, The International Journal of Accounting, 34(1), 49-70.

Yazdifar, H., \& Askarany, D. (2012). A comparative study of the adoption and implementation of Target costing in the UK, Australia and New Zealand, International Journal of Production Economics, 135(1), 382-392.

Yigitbasioglu, O.M. (2017). Drivers of management accounting adaptability: the agility lens, Journal of Accounting \& Organizational Change, 13(2), 262-281.

Zengin, Y., \& Ada, E. (2010). Cost management through product design: Target costing approach, International Journal of Production Research, 48 (19), 5591-5611. 